\title{
Robot-assisted minimally invasive esophagectomy: systematic review on surgical and oncological outcomes
}

\author{
Stefano Bongiolatti ${ }^{1}$, Arianna Farronato ${ }^{1}$, Michele Di Marino ${ }^{2}$, Mario Annecchiarico ${ }^{2}$, Francesco Coratti ${ }^{3}$, \\ Fabio Cianchi ${ }^{3}$, Andrea Coratti ${ }^{2}$, Luca Voltolini ${ }^{1}$ \\ 'Thoracic Surgery Unit, Careggi University Hospital, Florence 50134, Italy. \\ ${ }^{2}$ Division of Oncological and Robotic General Surgery, Careggi University Hospital, Florence 50134, Italy. \\ ${ }^{3}$ Division of Digestive Surgery, Careggi University Hospital, Florence 50134, Italy.
}

Correspondence to: Dr. Stefano Bongiolatti, Thoracic Surgery Unit, Careggi University Hospital, Largo Brambilla, 1, Florence 50134, Italy. E-mail: stefanobongiolatti@gmail.com

\begin{abstract}
How to cite this article: Bongiolatti S, Farronato A, Di Marino M, Annecchiarico M, Coratti F, Cianchi F, Coratti A, Voltolini L. Robot-assisted minimally invasive esophagectomy: systematic review on surgical and oncological outcomes. Mini-invasive Surg 2020;4:41. http://dx.doi.org/10.20517/2574-1225.2020.28
\end{abstract}

Received: 28 Feb 2020 First Decision: 1 Apr 2020 Revised: 15 Apr 2020 Accepted: 25 May 2020 Published: 12 Jul 2020

Academic Editor: Itasu Ninomiya Copy Editor: Cai-Hong Wang Production Editor: Jing Yu

\begin{abstract}
Aim: Esophagectomy is associated with several post-operative complications (50\%-70\%) due to surgical trauma. Minimally invasive techniques have therefore been applied to decrease mortality and morbidity. Robotassisted minimally-invasive esophagectomy (RAMIE) was developed to overcome the drawbacks of the thoracolaparoscopic approach. The objective of this systematic review is to report some recent experiences and to compare RAMIE with other approaches to esophagectomy, focusing on technical and oncological aspects.
\end{abstract}

Methods: Pubmed, Embase and Scopus databases were searched for "robot-assisted esophagectomy", "minimally invasive esophagectomy" and "robotic esophagectomy" in January 2020. The study was focused on original papers on totally endoscopic RAMIE in the English language. No statistical procedures (meta-analysis) were performed.

Results: Three hundred and twenty studies were identified across the database and after screening and reviewing, 14 were included for final analysis. The overall 90-day post-operative mortality after trans-thoracic esophagectomy ranged from $0 \%$ to $9 \%$ and did not differ between approaches. Post-operative complications ranged between $24 \%$ and $60.9 \%$ : respiratory $(6.25 \%$ to $65 \%$ ), cardiac $(0.8 \%$ to $32 \%$ ), anastomotic leak ( $3.1 \%$ and

\footnotetext{
(@) (-)

(C) The Author(s) 2020. Open Access This article is licensed under a Creative Commons Attribution 4.0 International License (https://creativecommons.org/licenses/by/4.0/), which permits unrestricted use, sharing, adaptation, distribution and reproduction in any medium or format, for any purpose, even commercially, as long as you give appropriate credit to the original author(s) and the source, provide a link to the Creative Commons license, and indicate if changes were made.
}

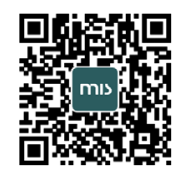


$37.5 \%)$ and vocal cord palsy (9.1\%-35\%) were the most frequent. The evidence for long-term outcomes is weak, with no significant differences in overall survival, disease-free survival and recurrence identified in comparison with other approaches. The selected papers showed that RAMIE had comparable outcomes between the open and thoraco-laparoscopic approaches within a multimodal treatment pathway.

Conclusion: RAMIE also seems to be associated with better lymph node dissection, nerve sparing and quality of life, but larger studies are needed to obtain more evidence.

Keywords: Robot-assisted minimally invasive esophagectomy, esophageal cancer, robotic surgery

\section{INTRODUCTION}

In the multimodal treatment pathway for esophageal carcinoma (EC), esophagectomy still remains an important component for curative and radical treatment. Current international guidelines ${ }^{[1-5]}$ recommend combined treatment for patients with localized esophageal or esophagogastric cancer and support the use of minimally invasive surgery such as minimally-invasive thoraco-laparoscopic esophagectomy (MIE) and also RAMIE. Esophagectomy is still associated with several post-operative complications ${ }^{[5]}$ due to surgical trauma and pre-operative clinical condition of the patient (advanced age, malnutrition, weight loss, chemoradiation). To reduce the consequent mortality and morbidity rates, surgeons have developed minimally invasive techniques also for a complex procedure such as esophagectomy ${ }^{[6-9]}$.

Furthermore, post-operative and oncological outcomes after esophagectomy are influenced by surgical volume and optimized by referral to specialized centers ${ }^{[10]}$. Several concerns have limited acceptance of MIE such as its technical complexity and doubts about its oncological value. The robotic platform (DaVinci system $^{\bullet}$ Intuitive Surgical Inc, Sunnyvale, CA) has several advantages that could overcome the drawbacks typical of MIE such as a magnified and three-dimensional endoscopic view, and articulated instruments with digitally filtered movements ${ }^{[11]}$. From the innovative and pioneering experiences of Giulianotti et al. ${ }^{[12]}$ and Kernstine et al ${ }^{[13]}$, RAMIE has gained popularity amongst surgeons because it seems to ensure adequate oncological outcomes with lower surgical trauma, and fewer post-operative complications in a stable and comfortable environment ${ }^{[14]}$. A recent randomized controlled trial $(\mathrm{RCT})^{[14]}$, a meta-analysis ${ }^{[15]}$ and some multicenter retrospective studies ${ }^{[16,17]}$ have demonstrated the safety and oncological adequacy of RAMIE, but other well-designed comparative long-term studies are needed to validate and establish the role of RAMIE.

The objective of this systematic review is to report some recent experiences and to compare RAMIE and other approaches for esophagectomy, with a focus on the technical and oncological aspects.

\section{Technical aspects of RAMIE}

\section{Indications}

The selection criteria and indications for RAMIE are the same as standard trans-thoracic open or MIE $\mathrm{E}^{[8-10]}$ and nowadays, some centers perform it after neo-adjuvant chemotherapy or radiation therapy ${ }^{[14,15,17]}$. Relative contraindications to MIE include: poor performance status, impaired lung function to tolerate one-lung ventilation, previous mediastinal surgery or extensive radiation therapy to the mediastinum ${ }^{[18]}$. Some types of esophagectomy are available, principally due to localization of the tumor, surgeon preference and the reconstructive options, but the most used are the trans-hiatal and trans-thoracic approaches with reconstruction of the digestive tract in the neck (McKeown esophagogastrostomy) or chest (Ivor Lewis esophagogastrostomy $)^{[18-22]}$. 


\section{Trans-hiatal RAMIE}

In this approach, the robotic platform is used only for gastrolysis, abdominal lymph node dissection, esophageal and mediastinal dissection and gastric tube reconstruction ${ }^{[19]}$. The anastomosis is performed in the neck ${ }^{[23,24]}$. The absence of thoracic incisions seems to be associated with lower post-operative respiratory complications and thus, this procedure could be proposed to patients with comorbidities such as chronic obstructive pulmonary disease and impaired lung function ${ }^{[19]}$. The mediastinal lymph node dissection includes only the para-esophageal and subcarinal stations ${ }^{[19]}$.

Trans-thoracic RAMIE with intrathoracic anastomosis (Ivor-Lewis procedure-ILE-)

With the patient supine, the first abdominal step includes complete mobilization of the stomach, preserving the blood supply from the right gastro-epiploic artery, celiac and splenic lymphadenectomy, hiatal and low mediastinal dissections and finally, gastric tube tailoring. Next, the thoracic phase is frequently performed in a full-lateral left decubitus, semi-prone or prone position with or without single-lung ventilation ${ }^{[24-27]}$. The prone position is associated with low pressure capnothorax that could decrease the incidence of postoperative respiratory complications, but some concerns could arise in the event of conversion. Nowadays, the preferred patient position is semi-prone ${ }^{[14,18,28]}$. Usually, four or five access ports are used anteriorly to the latissimus dorsi muscle $e^{[14,18,28,29]}$. The surgical steps are: complete intrathoracic mobilization of the esophagus; para-esophageal, subcarinal and para-tracheal lymph node dissection; and lastly, esophagogastric anastomosis above or at the level of the azygos vein ${ }^{[25-29]}$. Several types of anastomosis can be constructed in the chest and the choice depends on the surgeon's experience, skills and preference. Handsewn anastomosis can be performed with the robotic platform, but it did not show clear advantages in terms of reduced incidence of anastomotic leak or stricture, and is associated with longer operative times ${ }^{[20]}$. The last Xi DaVinci platform is armed with robotic staplers and some surgeons have shifted from handsewn to mechanical anastomosis ${ }^{[30]}$.

\section{Trans-thoracic RAMIE with cervical anastomosis (McKeown procedure-MKE-)}

Three-field esophagectomy starts with complete mediastinal mobilization, radical thoracic lymphadenectomy and esophageal dissection in the upper region of the chest ${ }^{[31]}$. As for the Ivor Lewis procedure, the McKeown's thoracic phase could be performed through the left lateral decubitus or prone position $^{[21,27,29,30]}$. After the thoracic phase, gastrolysis, celiac lymph node dissection and gastric conduit construction can be performed in the abdomen ${ }^{[2,29,30]}$. The gastric conduit is then pulled-up through the posterior mediastinum and the esophago-gastric anastomosis is performed in the neck ${ }^{[14,21]}$. The robotic platform ensures greater exposure for dissection of the upper region of the chest, reducing potential injury to vascular, respiratory (trachea and main bronchi) or nervous structures (vagus and recurrent laryngeal nerves) ${ }^{[14,32]}$.

\section{Technical aspects of anastomosis}

After three-field and trans-hiatal esophagectomy, the preferred techniques of cervical anastomosis are hand-sewn end-to-side and linear-stapled side-to-side anastomosis (modified Collard, Orringer) ${ }^{[3,34]}$.

According to the literature, esophagogastric anastomosis using the modified Collard method has lower rates of anastomotic leakage $(0 \%-18.4 \% v$ s. $0 \%-27 \%)$ and stricture $(0 \%-65.1 \% v \text { s. } 0 \%-89.9 \%)^{[35]}$.

The minimally-invasive intrathoracic anastomosis is considered a more challenging technique due to the reduced degree of freedom and less space for instrument handling and staplers. However, with the development of new equipment and the evolution of robotic platforms, some intrathoracic anastomosis techniques are now available: hand-sewn ${ }^{[25,26,36,37]}$, circular-stapled ${ }^{[28]}$, linear-stapled and trans-oral circularstapled $^{[38]}$. 
Table 1. Summary of selected papers on robot-assisted minimally-invasive esophagectomy-RAMIE

\begin{tabular}{|c|c|c|c|c|c|c|}
\hline Author & $\begin{array}{c}\text { Year of } \\
\text { publication }\end{array}$ & Type of study & LOE & GOR & $\begin{array}{l}\text { Number of } \\
\text { patients }\end{array}$ & Comments \\
\hline Boone et al. ${ }^{[18]}$ & 2009 & Retrospective study & $3 b$ & C & 47 & $\begin{array}{l}\text { One of the largest series of RAMIE for } \\
\text { EC published before } 2010 \text { with some } \\
\text { technical pitfalls and details }\end{array}$ \\
\hline Puntambekar et al. ${ }^{[27]}$ & 2011 & Retrospective study & 4 & D & 32 & $\begin{array}{l}\text { Retrospective study of RAMIE in prone } \\
\text { position }\end{array}$ \\
\hline Dunn et al. ${ }^{[19]}$ & 2012 & Retrospective study & $3 b$ & $\mathrm{D}$ & 40 & $\begin{array}{l}\text { The largest series of RAMIE with the } \\
\text { trans-hiatal approach, focusing on post- } \\
\text { operative and mid-term oncological } \\
\text { outcomes }\end{array}$ \\
\hline Sarkaria et al. ${ }^{[21]}$ & 2012 & Retrospective study & 4 & $\mathrm{D}$ & 21 & $\begin{array}{l}\text { Retrospective study of patients enrolled } \\
\text { over one year in a tertiary center }\end{array}$ \\
\hline Suda et al. ${ }^{[32]}$ & 2012 & Retrospective study & $3 b$ & C & 36 & $\begin{array}{l}\text { Technical report on RAMIE for SCC } \\
\text { focusing on lymph node dissection }\end{array}$ \\
\hline de la Fuente et $\left.a\right|^{[36]}$ & 2013 & Retrospective study & $3 b$ & C & 50 & $\begin{array}{l}\text { Retrospective study on Ivor-Lewis RAMIE } \\
\text { in a referral center }\end{array}$ \\
\hline Yerokun et al. ${ }^{[39]}$ & 2016 & $\begin{array}{l}\text { Retrospective propensity } \\
\text { matched study on NCDB }\end{array}$ & $3 b$ & C & 231 & $\begin{array}{l}\text { Population-based analysis of RAMIE } \\
\text { using a national database; comparison } \\
\text { between OE and MIE with regard to post- } \\
\text { operative outcomes and 3-year survival }\end{array}$ \\
\hline Weksler et al. ${ }^{[17]}$ & 2017 & $\begin{array}{l}\text { Retrospectivepropensity } \\
\text { matched study on NCDB }\end{array}$ & $3 b$ & C & 581 & $\begin{array}{l}\text { Population-based analysis of RAMIE } \\
\text { using a national database; comparison } \\
\text { between OE, MIE and RAMIE on survival }\end{array}$ \\
\hline van der Sluis et al. ${ }^{[14]}$ & 2018 & $\begin{array}{l}\text { Randomized controlled } \\
\text { trial }\end{array}$ & $1 b$ & A & 112 & $\begin{array}{l}\text { The only RCT published which compared } \\
\text { OE and RAMIE on post-operative and } \\
\text { oncological long term outcomes }\end{array}$ \\
\hline Harbison et al. ${ }^{[16]}$ & 2019 & $\begin{array}{l}\text { Retrospective study on } \\
\text { ACS-NSQIP database }\end{array}$ & $3 b$ & C & 725 & $\begin{array}{l}\text { Retrospective analysis of a national } \\
\text { database comparing RAMIE with MIE on } \\
\text { morbidity and mortality }\end{array}$ \\
\hline Yang et al. ${ }^{[22]}$ & 2019 & $\begin{array}{l}\text { Retrospectivepropensity } \\
\text { matched study }\end{array}$ & $3 b$ & C & 652 & $\begin{array}{l}\text { Large retrospective study which } \\
\text { compared MIE and MKE-RAMIE on } \\
\text { post-operative results and mid-term } \\
\text { oncological outcomes }\end{array}$ \\
\hline Tagkalos et al.. ${ }^{[28]}$ & 2019 & $\begin{array}{l}\text { Retrospective study } \\
\text { propensity matched study }\end{array}$ & $3 b$ & C & 100 & $\begin{array}{l}\text { Comparison between ILE-RAMIE and } \\
\text { ILE-MIE on post-operative outcomes }\end{array}$ \\
\hline Sarkaria et al.. & 2019 & $\begin{array}{l}\text { Prospective, non- } \\
\text { randomized trial }\end{array}$ & $2 b$ & $B$ & 106 & $\begin{array}{l}\text { Prospective trial which compared OE } \\
\text { and RAMIE focusing in particular on } \\
\text { post-operative outcomes, functional } \\
\text { assessment and quality of life }\end{array}$ \\
\hline Yun et $a{ }^{[29]}$ & 2019 & $\begin{array}{l}\text { Retrospective study } \\
\text { propensity matched study }\end{array}$ & $3 b$ & C & 371 & $\begin{array}{l}\text { Large retrospective analysis of the } \\
\text { comparison between RAMIE and OE for } \\
\text { SCC on post-operative outcomes and } \\
\text { mid-term survival }\end{array}$ \\
\hline
\end{tabular}

RAMIE: robot-assisted minimally-invasive esophagectomy; LOE: level of evidence; GOR: grade of recommendation; EC esophageal cancer; SCC: squamous cell carcinoma; NCDB: National Cancer Data Base; ACS-NSQIP: American College of Surgeons-National Surgical Quality Improvement Program; OE: open esophagectomy; MIE: minimally-invasive esophagectomy; RCT: randomized controlled trialL; MKE: McKeown esophagectomy; ILE: Ivor-Lewis esophagectomy

Large studies are needed to determine which technique is associated with less anastomotic complications, even if a group reported the shift from hand-sewn end-to-side intrathoracic anastomosis to linear-stapled, reducing the post-operative leak rates ${ }^{[30]}$.

\section{METHODS}

\section{Literature search}

Pubmed, Embase and Scopus databases were searched for "robot-assisted esophagectomy", "minimally invasive esophagectomy" and "robotic esophagectomy" in January 2020. This search was focused on original papers on totally endoscopic RAMIE (systematic reviews and papers about hybrid procedures were excluded) in the English language. Articles were screened for the type and year of publication, first author, number of patients, pre- and post-operative characteristics, post-operative complications and oncological outcomes by the authors Bongiolatti S and Farronato A. Baseline characteristics for all included studies 
Table 2. Study type, year of publication and main characteristics of the included studies

\begin{tabular}{|c|c|c|c|c|}
\hline Author & Type of esophagectomy & Conversions & EBL (mL) & Type of anastomosis \\
\hline Boone et $\left.a\right|^{[18]}$ & TT MKE & $7(15 \%)$ & 625 & Cervical handsewn end-to-side \\
\hline Puntambekar et al. ${ }^{[27]}$ & TT MKE & 0 & 80 & NA \\
\hline Dunn et al. ${ }^{[19]}$ & $\mathrm{TH}$ & $5(12.5 \%)$ & 97.2 & Cervical mechanical end-to-end \\
\hline Sarkaria et al. ${ }^{[21]}$ & TT ILE+MKE & $10(48 \%)$ & $307 \mathrm{~cm}^{3}$ & $\begin{array}{l}\text { Mechanical circular endo-to-end (ILE) } \\
\text { Cervical handsewn end-to-side (MKE) }\end{array}$ \\
\hline Suda et $a l^{[32]}$ & TT MKE & NA & 144 & $\begin{array}{l}\text { Cervical handsewn end-to-side or } \\
\text { cervical handsewn end-to-end }\end{array}$ \\
\hline de la Fuente et $a l_{.}^{[36]}$ & TT ILE & NA & 146 & NA \\
\hline Yerokun et al. ${ }^{[39]}$ & NA & $28(12.1 \%)$ & NA & NA \\
\hline Weksler et al. ${ }^{[17]}$ & NA & $6.7 \%$ & NA & NA \\
\hline van der Sluis et al. ${ }^{[14]}$ & TT MKE & $3(5 \%)$ & 120 & Cervical handsewn end to side \\
\hline Harbison et al. ${ }^{[16]}$ & $\mathrm{TT}$ & $11(11 \%)$ & NA & NA \\
\hline Yang et al. ${ }^{[22]}$ & TT MKE & $2(0.7 \%)$ & 211 & Cervical mechanical end-to-end \\
\hline Tagkalos et al. ${ }^{[28]}$ & TT ILE & NA & NA & Cervical mechanical end to side \\
\hline Sarkaria et al. ${ }^{[31]}$ & TT ILE+MKE & NA & 250 & NA \\
\hline Yun et al. ${ }^{[29]}$ & TT MKE+ILE & $3(2.3 \%)$ & 110 & Mechanical circular \\
\hline
\end{tabular}

EBL: estimated blood loss; TT: trans-thoracic; MKE: McKeown esophagectomy; ILE: Ivor-Lewis esophagectomy; NA: not available; TH: trans-hiatal

are summarized in Table 1. No formal statistical procedure (meta-analysis) was performed. One study was a $\mathrm{RCT}^{[14]}$, and the other 13 were observational studies including one prospective ${ }^{[31]}$ and 12 retrospective studies published from 2009 to 2019 . In addition, four papers had propensity-matched analysis ${ }^{[22,28,29,39]}$ and three were multi-center studies ${ }^{[16,17,39]}$.

\section{RESULTS}

Three-hundred and twenty studies were initially identified from the electronic databases and after screening and reviewing, 14 were included for final analysis. Table 2 shows the main characteristics of the included studies.

\section{Intra and post-operative outcomes}

Conversion rates were reported in ten papers and were much different from the early experience to the latest study [Table 2]. The largest multi-center studies, published in 2016 and 2017, showed a conversion rate ranging from $6.7 \%$ to $12.1 \%$; in the RCT, the rate is lower (5\%), probably due to the large experience gained by the Dutch group ${ }^{[14]}$. Operative time is significantly longer for RAMIE in comparison with open esophagectomy $(\mathrm{OE})^{[14,29,31]}$ and $\mathrm{MIE}^{[16,22,29]}$.

Dunn et al. ${ }^{[19]}$ in 2012 demonstrated the feasibility of the trans-hiatal approach in a cohort of 40 patients with $2.5 \%$ mortality at 30 days, but there was quite a high incidence of overall post-operative complications: anastomotic leaks without the need for re-operation $(n=10,25 \%)$; recurrent laryngeal nerve injuries $(n=$ $14,35 \%)$ and pneumonia $(n=8,20 \%)$ [Table 3]. The use of this approach has gradually decreased in favor of trans-thoracic esophagectomy because the lymph node dissection is more extensive with trans-thoracic esophagectomy and more accurate surgical and pathological staging could be obtained. Trans-hiatal MIE or RAMIE could be useful approaches in patients with severe lung function impairment or other relevant co-morbid conditions because one-lung ventilation and thoracic incisions are not required ${ }^{[9]}$.

The overall 90-day post-operative mortality rate after trans-thoracic esophagectomy was reported in ten papers and ranged between $0 \%$ to $9 \%$ without any difference between two or three field esophagecto my ${ }^{[14,16-19,22,28,29,31]}$. The RCT published by van der Sluis et al. ${ }^{[14]}$ reported comparable in-hospital mortality rates between patients who underwent RAMIE $(2 \%)$ and $\mathrm{OE}(4 \%)(P=0.62)$. The 90 -day mortality rate was not significantly higher for RAMIE patients $(2 \% v s .9 \% ; P=0.11)$. Multicenter analysis by Harbison et al. ${ }^{[16]}$ 
Table 3. Post-operative outcomes of RAMIE

\begin{tabular}{|c|c|c|c|c|c|c|}
\hline \multirow{2}{*}{ Author } & \multirow{2}{*}{$\begin{array}{l}\text { Post-operative } \\
\text { mortality 90day }\end{array}$} & \multicolumn{5}{|c|}{ Complications } \\
\hline & & Overall & Respiratory & Anastomotic & Cardiac & VCP \\
\hline Boone et $a l^{[18]}$ & $3(4.05 \%)$ & NA & $21(44.7 \%)$ & $10(21.3 \%)$ & $6(12.7 \%)$ & $9(19.1 \%)$ \\
\hline Puntambekar et al. ${ }^{[27]}$ & NA & NA & $2(6.25 \%)$ & $3(9 \%)$ & NA & NA \\
\hline Dunn et al. ${ }^{[19]}$ & $1(2.5 \%)$ & NA & $26(65 \%)$ & $10(25 \%)$ & NA & $14(35 \%)$ \\
\hline Sarkaria et al. ${ }^{[21]}$ & $1(5 \%)$ & $5(24 \%)$ & NA & $3(14 \%)$ & NA & $3(14 \%)$ \\
\hline Suda et al. ${ }^{[32]}$ & 0 & $8(50 \%)$ & $1(6.25 \%)$ & $6(37.5 \%)$ & $1(6.25 \%)$ & $6(37.5 \%)$ \\
\hline de la Fuente et $a{ }^{[36]}$ & NA & $14(28 \%)$ & $5(10 \%)$ & $2(4 \%)$ & $5(10 \%)$ & NA \\
\hline Yerokun et al. ${ }^{[39]}$ & NA & NA & NA & NA & NA & NA \\
\hline Weksler et al. ${ }^{[17]}$ & $7.8 \%$ & NA & NA & NA & NA & NA \\
\hline van der Sluis et al. ${ }^{[14]}$ & $5(9 \%)$ & $32(59 \%)$ & $17(32 \%)$ & $13(24 \%)$ & $17(32 \%)$ & $5(9.1 \%)$ \\
\hline Harbison et al. ${ }^{[16]}$ & $3(3 \%)$ & $31(31 \%)$ & $11(11 \%)$ & $14(14 \%)$ & NA & NA \\
\hline Yang et $a^{[22]}$ & 0 & $122(45 \%)$ & $71(25.3 \%)$ & $32(11.8 \%)$ & $9(3.3 \%)$ & $79(29 \%)$ \\
\hline Tagkalos et al. ${ }^{[28]}$ & $(5 \%)$ & NA & $(12 \%)$ & (12\%) & NA & NA \\
\hline Sarkaria et al..$^{[31]}$ & $1(1.56 \%)$ & $39(60.9 \%)$ & NA & $2(3.1 \%)$ & $5(7.8 \%)$ & $2(3.1 \%)$ \\
\hline Yunet al. ${ }^{[29]}$ & 0 & $49(37.7 \%)$ & NA & $4(3.1 \%)$ & $1(0.8 \%)$ & $33(25.4 \%)$ \\
\hline
\end{tabular}

VCP: vocal cord palsy; NA: not available

showed similar mortality between RAMIE and MIE (3\% vs. 2.24\%); other large retrospective studies have demonstrated that RAMIE had similar mortality rates when compared with MIE and $\mathrm{OE}^{[22]}$.

Post-operative complications were reported in eight studies and ranged between $24 \%$ and $60.9 \%^{[14,16,21,22,29,31,32]}$. Although it can now be performed through a minimally invasive approach, esophagectomy is still associated with a high incidence of overall complications. In the RCT, the overall complication rate was assessed at $59 \%{ }^{[14]}$; Harbison et al ${ }^{[16]}$ reported an overall morbidity rate of $31 \%$, while other large single-institution studies reported variable rates from $45 \%^{[22]}$ to $37.7 \%^{[29]}$.

The absence of thoracotomy did not avoid respiratory complications, which were reported in $6.25 \%$ to $65 \%$ of cases $^{[14,16,18,22,27,39]}$. Some possible mechanisms could be involved: prolonged one-lung ventilation, reduced cough reflex due to vagus nerve injury, alteration of swallowing and consequent aspiration, and the presence of comorbidities such as advanced age and chronic obstructive pulmonary disease ${ }^{[14,16,18,22,27,39]}$. Cardiac arrhythmias were frequent and reported in $0.8 \%$ to $32 \%$ of cases ${ }^{[18,22,29]}$.

Anastomotic complications are still the Achilles' heel of MIE and RAMIE. No subtype (mechanical $v s$. hand-sewn, end-to-end $v s$. end-to-side) nor location (cervical or intrathoracic) of esophagogastric anastomosis have shown to be more reliable and safer than others and even after RAMIE, the anastomotic complication rate is still significant and ranges between $3.1 \%$ and $37.5 \%$. Although data about anastomotic leak rates are available in most studies, anastomotic stricture is less frequently reported even if it has a negative impact on the quality of life. The $\mathrm{RCT}^{[14]}$ described the need of anastomotic dilatation in $52 \%$ of patients who underwent RAMIE, while other single institutional reports showed lower rates of stricture or anastomotic dilatation (4.7\%) and the majority of these patients underwent intrathoracic anastomosis ${ }^{[21]}$.

Although the robot-assisted platform has a magnified three-dimensional view, recurrent laryngeal nerve palsy was described in eight papers and it was frequently reported after cervical anastomosis (9.1\%-35\%), probably due to extensive lymph node dissection. Chylothorax is another frequent complication and assessed from $0 \%$ to $17 \%^{[14,21,22,29]}$; in the RCT, $4 \%$ of patients needed re-intervention for chylothorax ${ }^{[14]}$. Some centers perform a prophylactic thoracic duct ligation just above the diaphragm between the descending aorta and esophagus ${ }^{[14,27]}$.

Only two studies have focused their attention on quality of life after RAMIE, reporting controversial results: Sarkaria et al. ${ }^{[31]}$ evaluated the quality of life using the Functional Assessment of Cancer Therapy- 
Table 4. Post-operative and long-term oncological outcomes.

\begin{tabular}{|c|c|c|c|c|c|c|c|}
\hline Author & Induction therapy & Tumor type & $\begin{array}{l}\text { Mean } n \text { dissected } \\
\text { lymph nodes }\end{array}$ & Radicality & 3yOs & $5 y 0 S$ & DFS \\
\hline Boone et $a{ }^{\left[{ }^{[18]}\right.}$ & $3(4 \%)$ & $\begin{array}{l}\text { ADC } 29(61.7 \%) \\
\text { SCC } 18(38.3 \%)\end{array}$ & 29 & $36(76.6 \%)$ & NA & NA & NA \\
\hline Puntambekar et al. ${ }^{[27]}$ & NA & NA & NA & & NA & NA & NA \\
\hline Dunn et al. ${ }^{[19]}$ & $17(42,5 \%)$ & $\begin{array}{l}\text { ADC } 36(90 \%) \\
\text { SCC } 2(5 \%)\end{array}$ & 20 & $94.7 \%$ & NA & NA & NA \\
\hline Sarkaria et al. ${ }^{[21]}$ & $16(76 \%)$ & $\begin{array}{l}\text { ADC } 18(85 \%) \\
\text { SCC } 3(14 \%)\end{array}$ & 20 & $17(85 \%)$ & NA & NA & NA \\
\hline Suda et $a l_{.}^{[32]}$ & NA & SCC $100 \%$ & 37.5 & $14(87.5 \%)$ & NA & NA & NA \\
\hline de la Fuente et $a{ }^{[36]}$ & $35(70 \%)$ & $\begin{array}{l}\text { ADC } 46(92 \%) \\
\text { SCC } 3(6 \%)\end{array}$ & 20 & $100 \%$ & NA & NA & NA \\
\hline Yerokun et al. ${ }^{[39]}$ & $120(70.6 \%)$ & $\begin{array}{l}\text { ADC } 186(80.5 \%) \\
\text { SCC } 45(19.5 \%)\end{array}$ & 16 & NA & NA & NA & NA \\
\hline Weksler et al. ${ }^{[17]}$ & $412(70,9 \%)$ & $\begin{array}{l}\operatorname{ADC}(78.3 \%) \\
\operatorname{SCC}(21.7 \%)\end{array}$ & 16 & $553(95.2 \%)$ & 48 months & 48 months & NA \\
\hline van der Sluis et al. ${ }^{[14]}$ & 49 (94\%) & $\begin{array}{l}\text { ADC } 41(76 \%) \\
\text { SCC } 13(24 \%)\end{array}$ & 27 & $50(93 \%)$ & $50 \%$ & $50 \%$ & $26 \mathrm{~m}$ \\
\hline Harbison et al. ${ }^{[16]}$ & & $\begin{array}{l}\text { ADC } 68(68 \%) \\
\text { SCC } 8(8 \%)\end{array}$ & NA & NA & NA & NA & NA \\
\hline Yang et al..$^{[22]}$ & $30(10.7 \%)$ & NA & 19.3 & $263(93.9 \%)$ & NA & NA & NA \\
\hline Tagkalos et al. ${ }^{[28]}$ & NA & NA & 27 & NA & NA & NA & NA \\
\hline Sarkaria et al. ${ }^{[31]}$ & $48(75 \%)$ & $\begin{array}{l}\text { ADC } 59(93.7 \%) \\
\text { SCC } 4(6.3 \%)\end{array}$ & 25 & $62(96.9 \%)$ & $81.7 \%$ & NA & NA \\
\hline Yun et al. ${ }^{[29]}$ & $21(16.2 \%)$ & SCC $130(100 \%)$ & 39 & $127(97.7 \%)$ & $81.7 \%$ & NA & $49.2 \%$ \\
\hline
\end{tabular}

3yOS: three years overall survival; 5yOS: five years overall survival; DFS: disease-free survival; ADC: adenocarcinoma; SCC: squamous cell carcinoma; NA: not available

Esophageal (FACT-E) and Functional Assessment of Cancer Therapy-General (FACT-G) scores, demonstrating a return to pre-operative values only after four months, without difference between $\mathrm{OE}$ or RAMIE. van der Sluis et al. ${ }^{[14]}$ administered some validated questionnaires (Short Form-36, EORTCEuropean Organisation for Research and Treatment of Cancer-Quality-of-life Questionnaire Core 30, EORTC QLQ-OES18-Quality of Life Questionnaire Oesophageal Cancer Module-and EQ-5D-EuroQoL-5Dimension) at discharge and six weeks after esophagectomy, demonstrating that functional recovery after RAMIE was better and faster than after OE.

\section{Oncological outcomes}

Long-term outcomes after RAMIE are still scarce, but data from a large multi-center study ${ }^{[17]}$ and from the only $\mathrm{RCT}^{[14]}$ showed encouraging results [Table 4]. Trans-thoracic esophagectomy seems to ensure more extensive lymph node dissection than the trans-hiatal approach and in particular, the mean number of retrieved lymph nodes was reported between 5 and 39. Furthermore, trans-thoracic esophagectomy was associated with a complete resection rate between $76.6 \%$ and $100 \%$. On the other hand, few papers have reported long-term oncological results: the only $\mathrm{RCT}^{[12]}$ showed that there were no statistically significant differences between OE and RAMIE in overall survival (OS) (log rank $P=0.427$ ) at 40 months of followup. Moreover, the authors demonstrated no statistical differences regarding disease-free survival (DFS) (26 for RAMIE vs. 28 months for OE) and recurrence pattern.

In their analysis of the National Cancer Data Base (NCDB), Weksler et al. ${ }^{[17]}$ showed 48 months of overall survival after RAMIE, this outcome was not different in comparison with the oncological results obtained by OE and MIE also after the propensity-matched analysis $(P=0.121$ and $P=0.53)$. With the magnified view and extreme precision of the articulated instruments, RAMIE is increasingly being used after induction treatments: in the RCT, $79 \%$ of patients were previously treated with chemo-radiation and in other studies, a large portion of patients were treated before surgery with chemotherapy alone $(70.9 \%-75 \%)^{[16,17]}$ or combined treatments $(68 \%-75 \%)^{[17,21,39]}$. 
Dunn et al ${ }^{[19]}$ in 2012 achieved $94.7 \%$ of radical resection with a median of 20 lymph nodes retrieved and a median overall survival of 20 months after trans-hiatal RAMIE. Another paper regarding laparoscopic trans-hiatal esophagectomy showed a median overall survival of 28 months with $3.7 \%$ of local recurrence, $22 \%$ regional and $37 \%$ distant recurrence ${ }^{[23]}$.

\section{DISCUSSION}

RAMIE has gained popularity in the past decade due to increased experience in Western countries and the availability of the robotic platform through Eastern countries, where the incidence of esophageal carcinoma is higher. Large multi-center studies and RCTs have demonstrated that minimally-invasive esophagectomy is safe and oncologically adequate, but it is a technically demanding procedure due to drawbacks from thoracoscopy and laparoscopy ${ }^{[1,5-9]}$.

The robot-assisted approach has some advantages over the thoraco-laparoscopic one: first, the magnified and three-dimensional intra-corporeal view; secondly, better dexterity due to the articulated instruments with tremor filtering, which allows fine dissection of mediastinal and abdominal structures; and finally, longer instruments with the fulcrum inside the body instead of the abdominal or chest wall, which could decrease post-operative pain. On the other hand, the lack of tactile feedback, longer operative time and costs are the main reported disadvantages of RAMIE. The latest version of the available robotic platform (DaVinci Xi), has four arms that work in a more parallel way than the previous version and with longer instruments, that facilitates meticulous dissection in narrow fields such as the esophageal hiatus and the upper region of the thorax ${ }^{[10,14,40]}$. The visceral and lymph node dissections in the cervico-mediastinal outlet could be more accurate and ergonomic with the RAMIE approach, avoiding injuries to other nervous, vascular or respiratory structures. Furthermore, these characteristics have a significant impact on lymph node dissection such that it can be performed in a safe manner due to the magnified view of the operating field and the small instrument tips. Some studies have demonstrated that lymph node dissection in the celiac area, subcarinal and paratracheal is safe and oncologically adequate with reduced nerve injury with $\operatorname{RAMIE}^{[32]}$.

Moreover, for tumors of the esophagogastric junction or lower thoracic esophagus, the robotic platform permits easy handling of instruments to perform hand-sewn or mechanical intrathoracic anastomosis $^{[20,21,25,26,36]}$. Anastomotic leak is still the Achilles' heel of esophagectomy and no anastomotic subtype was superior in terms of leakage or stricture. Some factors are associated with anastomotic leaks and a poorly perfused conduit is a well-known risk factor for anastomotic dehiscence. This issue could be reduced with the use of NRF (Near InfraRed Fluorescence) associated with the intravenous administration of indocyanine green. With NRF, the surgeon could obtain a real-time gastric conduit perfusion, identifying inadequately perfused or ischemic areas and then the surgeon could construct the esophagogastric anastomosis on a well-perfused conduit ${ }^{[30,41]}$. Moreover, the latest robotic platform is armed with robotic staplers and the surgeon can create a mechanical end-to-side esophagogastric anastomosis with easier handling.

Although evidence about RAMIE are still weak, data from large institutional studies and from the only published RCT supported the application of RAMIE in the treatment of EC in a multimodal treatment pathway ${ }^{[3,4,10,42]}$. Some recent papers reported a variable, but high use of induction chemotherapy and chemoradiation therapy with potentially improved long-term results. Long-term OS and DFS were evaluated in few papers, but RAMIE was demonstrated not to be inferior to MIE or $\mathrm{OE}^{[14,17,22,31]}$.

The main issue of robot-assisted surgery remains the high costs to buy the platform and instruments, to start a program and for periodical technical assistance. The actual monopoly of Intuitive Surgical is 
undesirable, but competitors are now present on the market and could improve developments, diffusion of ideas and decreasing the costs of robot-assisted surgery.

In conclusion, although possible with a minimally-invasive approach, trans-thoracic esophagectomy is still associated with significant post-operative complications. It has demonstrated acceptable oncological outcomes in terms of radicality, lymph node dissection, overall and disease-free survival. The robotic platform has shown some advantages in lymph node dissection, nerve sparing, improved intra-thoracic anastomosis and faster recovery after surgery, but large studies are necessary to understand the actual role of RAMIE in the multimodal treatment of EC.

\section{DECLARATIONS}

\section{Authors' contributions}

Conceptualization:Bongiolatti S

Data collection: Bongiolatti S, Farronato A

Formal Analysis, investigation, methodology, project administration, resources and software: Bongiolatti S Supervision: Bongiolatti S, Voltolini L

Validation and visualization: all authors

Writing-original draft and writing-review and editing: Bongiolatti $S$

\section{Availability of data and materials}

Not applicable.

\section{Financial support and sponsorship}

None.

\section{Conflicts of interest}

All authors declared that there are no conflicts of interest.

\section{Ethical approval and consent to participate}

Not applicable.

\section{Consent for publication}

Not applicable.

\section{Copyright}

(c) The Author(s) 2020.

\section{REFERENCES}

1. NCCN Clinical Practice Guidelines in Oncology $\left(\mathrm{NCCN}\right.$ Guidelines $\left.{ }^{\circledR}\right)$ Esophageal and Esophagogastric Junction Cancers. Version 4.2019 - December 20, 2019 NCCN.org https://www.ncen.org

2. Lordick F, Mariette C, Haustermans K, Obermannová R, Arnold D; ESMO Guidelines Committee. Oesophageal cancer: ESMO Clinical Practice Guidelines for diagnosis, treatment and follow-up. Ann Oncol 2016;27:v50-7.

3. Cunningham D, Allum WH, Stenning SP, Thompson JN, Van de Velde CJ, et al. Perioperative chemotherapy versus surgery alone for resectable gastroesophageal cancer. N Engl J Med 2006;355:11-20.

4. Cooper JS, Guo MD, Herskovic A, Macdonald JS, Martenson Jr JA, et al. Chemoradiotherapy of locally advanced esophageal cancer: long-term follow-up of a prospective randomized trial (RTOG 85-01). Radiation Therapy Oncology Group. JAMA 1999;281:1623-7.

5. Enzinger PC, Mayer RJ. Esophageal cancer. N Engl J Med 2003;349:2241-52.

6. Safranek PM, Cubitt J, Booth MI, Dehn TC. Review of open and minimal access approaches to oesophagectomy for cancer. Br J Surg 2010;97:1845-53.

7. Straatman J, Van Der Wielen N, Cuesta MA, Daams F, Garcia JR, et al. Minimally invasive versus open esophageal resection: three-year follow-up of the previously reported randomized controlled trial: the TIME trial. Ann Surg 2017;266:232-6. 
8. Biere SS, van Berge Henegouwen MI, Maas KW, Bonavina L, Rosman C, et al. Minimally invasive versus open oesophagectomy for patients with oesophageal cancer: a multicentre, open-label, randomised controlled trial. Lancet 2012;379:1887-92.

9. Luketich JD, Pennathur A, Awais O, Levy RM, Keeley S, et al. Outcomes after minimally invasive esophagectomy: review of over 1000 patients. Ann Surg 2012;256:95-103.

10. van der Sluis PC, Ruurda JP, van der Horst S, Goense L, van Hillegersberg R. Learning curve for robot-assisted minimally invasive thoracoscopic esophagectomy: results from 312 cases. Ann Thorac Surg 2018;106:264-71.

11. Ruurda JP, van der Sluis PC, van der Horst S, van Hilllegersberg R. Robot-assisted minimally invasive esophagectomy for esophageal cancer: a systematic review. J Surg Oncol 2015;112:257-65.

12. Giulianotti PC, Coratti A, Angelini M, Sbrana F, Cecconi S, et al. Robotics in general surgery: personal experience in a large community hospital. Arch Surg 2003;138:777-84.

13. Kernstine KH, DeArmond DT, Karimi M, Van Natta TL, Campos JH, et al. The robotic, 2-stage, 3-field esophagolymphadenectomy. J Thorac Cardiovasc Surg 2004;127:1847-9.

14. van der Sluis PC, van der Horst S, May AM, Schippers C, Brosens LAA, et al. Robot-assisted minimally invasive thoracolaparoscopic esophagectomy versus open transthoracic esophagectomy for resectable esophageal cancer: a randomized controlled trial. Ann Surg 2019;269:621-30.

15. Jin D, Yao L, Yu J, Liu R, Guo TK, et al. Robotic-assisted minimally invasive esophagectomy versus the conventional minimally invasive one: a meta-analysis and systematic review. Int J Med Robot 2019;15:e1988.

16. Harbison GJ, Vossler JD, Yim NH, Murayama KM. Outcomes of robotic versus non-robotic minimally-invasive esophagectomy for esophageal cancer: an American college of surgeons NSQIP database analysis. Am J Surg 2019;218:1223-8.

17. Weksler B, Sullivan JL. Survival after esophagectomy: a propensity-matched study of different surgical approaches. Ann Thorac Surg 2017;104:1138-46.

18. Boone J, Schipper ME, Moojen WA, Borel Rinkes IH, Cromheecke GJ, et al. Robot-assisted thoracoscopic oesophagectomy for cancer. Br J Surg 2009;96:878-86.

19. Dunn DH, Johnson EM, Morphew JA, Dilworth HP, Krueger JL, et al. Robot-assisted transhiatal esophagectomy: a 3-year single-center experience. Dis Esophagus 2013;26:159-66.

20. Cerfolio RJ, Bryant AS, Hawn MT. Technical aspects and early results of robotic esophagectomy with chest anastomosis. J Thorac Cardiovasc Surg 2013;145:90-6.

21. Sarkaria IS, Rizk NP, Finley DJ, Bains MS, Adusumilli PS, et al. Combined thoracoscopic and laparoscopic robotic-assisted minimally invasive esophagectomy using a four-arm platform: experience, technique and cautions during early procedure development. Eur J Cardiothorac Surg 2013;43:e107-15.

22. Yang Y, Zhang X, Li B, Hua R, He Y, et al. Short-and mid-term outcomes of robotic versus thoraco-laparoscopic McKeown esophagectomy for squamous cell esophageal cancer: a propensity score-matched study. Dis Esophagus 2019; doz080.

23. Puntambekar S, Gauba Y, Chitale M, Manchekar M, Panse M, et al. Evaluation of 5-year results of laparoscopic transhiatal oesophagectomy as a single-centre experience. J Minim Access Surg 2019;15: 331-5.

24. DePaula AL, Hashiba K, Ferreira EA, de Paula RA, Grecco E. Laparoscopic transhiatal esophagectomy with esophagogastroplasty. Surg Laparosc Endosc 1995;5:1-5.

25. Trugeda S, Fernández-Díaz MJ, Rodríguez-Sanjuán JC, Palazuelos CM, Fernández-Escalante C, et al. Initial results of robot-assisted Ivor-Lewis oesophagectomy with intrathoracic hand-sewn anastomosis in the prone position. Int J Med Robot 2014;10:397-403.

26. Bongiolatti S, Annecchiarico M, Di Marino M, Boffi B, Borgianni S, et al. Robot-sewn Ivor-Lewis anastomosis: preliminary experience and technical details. Int J Med Robot 2016;12:421-6.

27. Puntambekar SP, Rayate N, Joshi S, Agarwal G. Robotic transthoracic esophagectomy in the prone position: experience with 32 patients with esophageal cancer. J Thorac Cardiovasc Surg 2011;142:1283-4.

28. Tagkalos E, Goense L, Hoppe-Lotichius M, Ruurda JP, Babic B, et al. Robot-assisted minimally invasive esophagectomy (RAMIE) compared to conventional minimally invasive esophagectomy (MIE) for esophageal cancer: a propensity-matched analysis. Dis Esophagus 2020;33:doz060.

29. Yun JK, Chong BK, Kim HJ, Lee IS, Gong CS, et al. Comparative outcomes of robot-assisted minimally invasive versus open esophagectomy in patients with esophageal squamous cell carcinoma: a propensity score-weighted analysis. Dis Esophagus 2020;33:doz071.

30. Guerra F, Vegni A, Gia E, Amore Bonapasta S, Di Marino M, et al. Early experience with totally robotic esophagectomy for malignancy. Surgical and oncological outcomes. Int J Med Robot 2018;14:e1902.

31. Sarkaria IS, Rizk NP, Goldman DA, Sima C, Tan KS, et al. Early quality of life outcomes after robotic-assisted minimally invasive and open esophagectomy. Ann Thorac Surg 2019;108:920-8.

32. Suda K, Ishida Y, Kawamura Y, Inaba K, Kanaya S, et al. Robot-assisted thoracoscopic lymphadenectomy along the left recurrent laryngeal nerve for esophageal squamous cell carcinoma in the prone position: technical report and short-term outcomes. World J Surg 2012;36:1608-16.

33. Collard JM, Romagnoli R, Goncette L, Otte JB, Kestens PJ. Terminalized semimechanical side-to-side suture technique for cervical esophagogastrostomy. Ann Thorac Surg 1998;65:814-7.

34. Orringer MB, Marshall B, Iannettoni MD. Eliminating the cervical esophagogastric anastomotic leak with a side-to-side stapled anastomosis. J Thorac Cardiovasc Surg 2000;119:277-88.

35. Deng XF, Liu QX, Zhou D, Min JX, Dai JG. Hand-sewn vs linearly stapled esophagogastric anastomosis for esophageal cancer: a meta- 
analysis. World J Gastroenterol 2015;21:4757-64.

36. de la Fuente SG, Weber J, Hoffe SE, Shridhar R, Karl R, et al. Initial experience from a large referral center with robotic-assisted Ivor Lewis esophagogastrectomy for oncologic purposes. Surg Endosc 2013;27:3339-47.

37. Elshaer M, Gravante G, Tang CB, Jayanthi NV. Totally minimally invasive two-stage esophagectomy with intrathoracic hand-sewn anastomosis: short-term clinical and oncological outcomes. Dis Esophagus 2018;31:dox150.

38. Campos GM, Jablons D, Brown LM, Ramirez RM, Rabl C, et al. A safe and reproducible anastomotic technique for minimally invasive Ivor Lewis oesophagectomy: the circular-stapled anastomosis with the trans-oral anvil. Eur J Cardiothorac Surg 2010;37:1421-6.

39. Yerokun BA, Sun Z, Yang CJ, Gulack BC, Speicher PJ, et al. Minimally invasive versus open esophagectomy for esophageal cancer: a population-based analysis. Ann Thorac Surg 2016;102:416-23.

40. van der Horst S, de Maat MFG, van der Sluis PC, Ruurda JP, van Hillegersberg R. Extended thoracic lymph node dissection in roboticassisted minimal invasive esophagectomy (RAMIE) for patients with superior mediastinal lymph node metastasis. Ann Cardiothorac Surg 2019;8:218-25.

41. Zehetner J, DeMeester SR, Alicuben ET, Oh DS, Lipham JC, et al. Intraoperative assessment of perfusion of the gastric graft and correlation with anastomotic leaks after esophagectomy. Ann Surg 2015;262:74-8.

42. Oppedijk V, van der Gaast A, van Lanschot JJ, van Hagen P, van Os R, et al. Patterns of recurrence after surgery alone versus preoperative chemoradiotherapy and surgery in the CROSS trials. J Clin Oncol 2014;32:385-91. 